\title{
Intoxicação experimental por Sida carpinifolia (Malvaceae) em ovinos $^{1}$
}

\author{
Anderson L. Seitz ${ }^{2 *}$, Edson M. Colodel ${ }^{2,}$ Severo S. Barros ${ }^{3}$ e David Driemeier ${ }^{2}$
}

\begin{abstract}
Seitz A.L., Colodel E.M., Barros S.S. \& Driemeier D. 2005. [Experimental poisoning by Sida carpinifolia (Malvaceae) in sheep.] Intoxicação experimental por Sida carpinifolia (Malvaceae) em ovinos. Pesquisa Veterinária Brasileira 25(1):15-20. Departamento de Patologia Clínica Veterinária, Faculdade de Veterinária, Universidade Federal do Rio Grande do Sul, Porto Alegre, RS 91540-000, Brazil.E-mail: alseitz@terra.com.br.

Seven sheep received dry crushed Sida carpinifolia L.f. One of them died at 18 and other at 53 days of the experiment. Four others were euthanatized and necropsied at 30, 45, 75 and 100 days. For one sheep the supply of S. carpinifolia was interrupted on the 80th day of the experiment, and 70 days later the animal was euthanized and necropsied. The minimal amount of the dry plant consumed was $11 \mathrm{~g} / \mathrm{kg}$ and the maximum was $30 \mathrm{~g} / \mathrm{kg}$. The progression of clinical findings was similar in six animals with slight diarrhea at 20 days of experiment. Neurological signs were observed at 25 days and included ataxia with dysmetria, muscle tremors of the head, atypical postural reactions, frequent falls, sluggish of movements, difficulty in grazing and swallowing. These signs were enhanced when the animals were forced to walk. Four of the animals presented progressive emaciation. The sheep whose supply of the plant was interrupted recovered gradually, and 11 days after the animal returned to normal. During necropsy, only enlarged mesenteric lymph nodes were observed. The histological alterations were more significant in the central nervous system, with multiple and severe cytoplasmic distention and vacuolation which affects specially Purkinje cells of the cerebellum, neurons of cerebral cortex, thalamus, midbrain and the ventral horn of spinal cord. Axonal spheroids in the brain, more frequently in the granular layer of cerebellum were also observed. The cytoplasmic vacuolation was also found in pancreatic acinar cells, renal tubules, thyroid follicular epithelium, hepatocytes and macrophages of lymphoid organs. The ultrastructural lesions observed were cytoplasmic vacuolation, some surrounded by membranes in Purkinje cells of cerebellum and thyroid follicular cells. The sheep, which had S. carpinifolia withdrawn from its diet for 70 days, had no significant histological alterations.
\end{abstract}

INDEX TERMS: Toxic plants, plant poisoning, Sida carpinifolia, Malvaceae, lysosomal storage disease, swainsonine, electronic microscopy.

RESUMO.- Administrou-se Sida carpinifolia L.f. secada à sombra e moída, em doses diárias de 11 a $30 \mathrm{~g} / \mathrm{kg} / \mathrm{dia}$, para sete ovinos. Um animal foi encontrado morto aos 18 e outro morreu apresentando sinais clínicos aos 53 dias do início do experimento. Outros quatro animais adoeceram e foram eutanasiados aos 30, 45, $75 \mathrm{e}$ 100 dias do experimento. 0 fornecimento de $S$. carpinifolia foi interrompido em um ovino ao $80^{\circ}$ dia do experimento, e o animal

\footnotetext{
${ }^{1}$ Recebido em 25 de maio de 2004.

Aceito para publicação em 8 de dezembro de 2004.

2 Depto Patologia e Clínica Veterinária, Faculdade de Veterinária, Universidade Federal do Rio Grande do Sul, (UFRGS), Cx. Postal 15094, Porto Alegre, RS 91540-000. *Autor para correspondência. E-mail: alseitz@terra.com.br

${ }^{3}$ Pesquisador Visitante da UFRGS e Bolsista da Fundação de Amparo à Pesquisa do Estado do Rio Grande do Sul (FAPERGS).
}

foi eutanasiado 70 dias após. Todos os animais foram necropsiados. O consumo variou entre 11 e $30 \mathrm{~g} / \mathrm{kg} / \mathrm{dia}$ da planta seca. As principais alterações clínicas iniciaram a partir do $20^{\circ}$ dia com emaciação progressiva e leve diarréia. Os sinais neurológicos iniciaram no $25^{\circ}$ dia e eram caracterizados por ataxia com dismetria, tremores da cabeça, posturas atípicas, quedas freqüentes, lentidão dos movimentos, dificuldade em apreender e deglutir os alimentos. Esses sinais clínicos se acentuavam quando os animais eram forçados a se movimentar. $\mathrm{O}$ ovino que parou de consumir Sida carpinifolia, recuperou-se clinicamente e 11 dias após a interrupção não apresentava mais alterações clínicas. Na necropsia havia aumento de volume dos linfonodos mesentéricos em cinco dos sete ovinos. Ao exame histológico as alterações mais significativas estavam presentes no sistema nervoso central e constavam de distensão e vacuolização citoplasmáticas afetando principalmente as células de Purkinje do cerebelo, os neurônios do 
córtex cerebral, do tálamo, do mesencéfalo e dos cornos ventrais da medula espinhal. Também foram observados esferóides axonais mais freqüentes na camada granular do cerebelo. A vacuolização citoplasmática foi observada também no epitélio dos ácinos pancreáticos e dos túbulos renais, nas células foliculares da tireóide, nos hepatócitos e macrófagos de órgãos linfóides. As lesões ultraestruturais observadas foram vacuolizações citoplasmáticas, algumas envoltas por membranas, em neurônios de Purkinje do cerebelo e nas células foliculares da tireóide. $O$ ovino que permaneceu 70 dias sem consumir S. carpinifolia não apresentou alterações histológicas.

TERMOS DE INDEXAÇÃO: Plantas tóxicas, intoxicação por planta, Sida carpinifolia, Malvaceae, doença do armazenamento lisossomal, swainsonina, locoweeds, microscopia eletrônica.

\section{INTRODUÇÃO}

A Sida carpinifolia (L.f.) K.Schum. pertence à família Malvaceae. É popularmente conhecida como guanxuma, malva-brava, cháda-índia e vassoura (Henriques et al. 1989, Lorenzi 2000b). É nativa das Américas, ocorre em lugares sombreados e se propaga por sementes (Lorenzi 2000b). No Brasil, se distribui nas regiões Sul, Sudeste e Centro-Oeste e é considerada uma importante erva daninha na agricultura (Bacchi et al. 1982, Lorenzi 2000a).

Foram relatados surtos naturais de intoxicação por Sida carpinifolia em caprinos (Driemeier et al. 2000, Colodel et al. 2002a), em pôneis, (Loretti et al. 2003) e em ovinos (Seitz et al. 2002). A doença foi reproduzida em caprinos, pela administração por via oral da planta seca, observando-se os primeiros sinais clínicos após o consumo de $10 \mathrm{~g} / \mathrm{kg}$ após o 35을 (Colodel et al. 2002).

$O$ alcalóide indolizidínico 1,2,8-triol, denominado swainsonina, presente na S. carpinifolia (Dorling et al. 1980, Colodel et al. 2002) é encontrado também em plantas dos gêneros Oxytropis sp (Stegelmeier et al. 1995), Astragalus sp (James et al. 1981, Harris et al. 1988) e Ipomoea sp. (Armién 2000, Tokarnia et al. 2000). Esse alcalóide induz a doença do armazenamento lisossomal, pois inibe as enzimas $\alpha$-manosidase lisossomal e $\alpha$ manosidase II do complexo de Golgi (Agamanolis 1995, King \& Alroy 2000, Moremen 2002).

O presente estudo foi realizado para determinar a toxicidade, caracterizar o quadro clínico, as alterações macroscópicas, histológicas e ultra-estruturais da intoxicação por Sida carpinifolia em ovinos.

\section{MATERIAL E MÉTODOS}

\section{Classificação botânica, coleta e processamento de Sida carpinifolia}

Amostras da planta utilizadas no experimento foram identificadas como Sida carpinifolia L.f., na Fundação Zoobotânica do Rio Grande do Sul, Porto Alegre, RS. A planta usada no experimento foi coletada, entre setembro e dezembro de 2001, no município de Viamão, RS, foi secada à sombra e moída em moinho martelo (peneira $8 \mathrm{~mm}$ ). $O$ volume de planta fornecido aos animais era previamente pesado, descontando-se as sobras ao final de 24 horas, para cálculo do consumo diário.
Quadro 1. Delineamento do experimento com Sida carpinifolia em ovino

\begin{tabular}{|c|c|c|c|c|c|c|}
\hline \multirow{2}{*}{$\begin{array}{c}\text { Ovino } \\
\text { no. }\end{array}$} & \multirow{2}{*}{$\begin{array}{c}\text { Idade } \\
\text { (meses) }\end{array}$} & \multicolumn{2}{|c|}{ Peso (kg) } & \multirow[t]{2}{*}{ Sexo } & \multirow{2}{*}{$\begin{array}{c}\text { Período de } \\
\text { consumo (dias) }\end{array}$} & \multirow{2}{*}{$\begin{array}{l}\text { Consumo } \\
\text { (g/kg/dia) }\end{array}$} \\
\hline & & Inicial & Final & & & \\
\hline 1 & 6 & 16 & 15 & Fêmea & 18 & 14 \\
\hline 2 & 6 & 17 & 19,2 & Fêmea & 30 & 30 \\
\hline 3 & 6 & 18 & 16,7 & Fêmea & 45 & 20 \\
\hline 4 & 8 & 19 & 19 & Macho & 53 & 20 \\
\hline 5 & 12 & 19 & 18 & Fêmea & 75 & 20 \\
\hline 6 & 12 & 21 & 20,2 & Macho & 80 & 20 \\
\hline 7 & 24 & 85 & 58 & Macho & 100 & 11 \\
\hline
\end{tabular}

\section{Animais experimentais}

Foram utilizados sete ovinos, numerados de 1 a 7 . 0 delineamento do experimento quanto, às características dos animais, às oscilações dos pesos dos animais, à quantia consumida e ao período de consumo da planta estão resumidos no Quadro 1. Os ovinos eram provenientes de área livre de $S$. carpinifolia e foram alojados em baias individuais. Adicionalmente, todos receberam feno de alfafa, ração comercial para ovinos peletizada e água à vontade.

\section{Estudo clínico e patológico}

Exames clínicos diários consistiram de avaliação postural, movimentação, comportamento e HR "Head Raising Test" [HR Test] (Pienaar et al. 1976) que consiste em estender caudodorsalmente a cabeça do animal em estação durante 1 minuto e, em seguida, soltá-la subitamente.

Com exceção dos Ovinos 1 e 4 que morreram, os demais foram eutanasiados ${ }^{4}$ e necropsiados, com intervalos pré-determinados. Foram utilizados, como controle os tecidos de cinco ovinos que não consumiram S. carpinifolia.

Durante a necropsia, foram coletados o sistema nervoso central e fragmentos de globo ocular, gânglio trigêmeo e celíaco, nervo ciático, linfonodos, coração, pulmão, baço, fígado, rim, medula óssea, bexiga, intestinos, rúmen, retículo, omaso, abomaso, traquéia, esôfago, testículo, epidídimo, ovário, útero, pele, pâncreas, hipófise, tireóide, adrenal, junção costo-condral e músculos esqueléticos e fixados em solução de formalina $10 \%$ tamponada, processados pelos métodos rotineiros para estudo histopatológico, e após inclusão em parafina os fragmentos foram cortados em micrótomo e corados pela técnica de hematoxilina e eosina (HE) (Prophet et al. 1992). Para estudo histológico do encéfalo, foram estudadas secções transversais do córtex cerebral e corpo estriado sobre o quiasma óptico, córtex cerebral e tálamo sobre o corpo mamilar, mesencéfalo sobre o colículo rostral, cerebelo sobre o pedúnculo cerebelar caudal e medula oblonga sobre o óbex. A medula espinhal foi avaliada, através de cortes transversais nos segmentos: cervical, torácico, lombar e intumescências cervical e lombar.

Fragmentos de cerebelo, pâncreas, fígado, linfonodo mesentérico, tireóide e medula cervical dos Ovinos 5 e 7 foram

\footnotetext{
${ }^{4}$ Os procedimentos de eutanásia foram realizados administrando-se Thionembutal ${ }^{\circledR}$ (Tiopental sódico) por via intravenosa, rápido e a efeito (Booth \& McDonald 1992, Massone 1999, Conselho Federal de Medicina Veterinária, Resolução no. 714, de 20 de junho de 2002).
} 
Quadro 2. Aspectos clínicos e patológicos observados em ovinos com experimentalmente intoxicados por Sida carpinifolia

\begin{tabular}{|c|c|c|c|c|c|c|}
\hline $\begin{array}{l}\text { Ovino } \\
\text { no. }\end{array}$ & $\begin{array}{l}\text { Consumo } \\
\text { (dias) }\end{array}$ & ISC $^{\mathrm{a}}$ & Principais manifestações clínicas & $\begin{array}{c}\text { Alterações } \\
\text { macroscópicas }\end{array}$ & $\begin{array}{l}\text { Alterações } \\
\text { microscópicas }\end{array}$ & $\begin{array}{c}\text { Alterações } \\
\text { ultra-estruturais }\end{array}$ \\
\hline 1 & 18 & $\mathrm{SA}^{\mathrm{b}}$ & SA & SA & $\begin{array}{l}\text { Vacuolização nos neurônios do corno ven- } \\
\text { tral da medula espinhal, na região cervical. }\end{array}$ & $N A^{c}$ \\
\hline 2 & 30 & 20 & $\begin{array}{l}\text { Fezes pastosas, alterações no HR Test, } \\
\text { tremor, queda, decúbito lateral, movi- } \\
\text { mentos de pedalagem, dificuldade para } \\
\text { ficar em estação e tremor intencional. }\end{array}$ & SA & $\begin{array}{l}\text { Distensão citoplasmática nas células de } \\
\text { Purkinje do cerebelo e dos neurônios do } \\
\text { corno ventral da medula espinhal. }\end{array}$ & NA \\
\hline 3 & 45 & 30 & $\begin{array}{l}\text { Tremor intencional discreto, olhar atô- } \\
\text { nito a partir do } 30^{\circ} \text { dia. }\end{array}$ & $\begin{array}{l}\text { Aumento de volume } \\
\text { dos linfonodos me- } \\
\text { sentéricos e emaciação. }\end{array}$ & $\begin{array}{l}\text { Distensão e vacuolização citoplasmática nas } \\
\text { células de Purkinje do cerebelo e nos neurô- } \\
\text { nios do corno ventral da medula espinhal. }\end{array}$ & NA \\
\hline 4 & 53 & 25 & $\begin{array}{l}\text { Fezes pastosas, letargia e tremores de } \\
\text { cabeça que aumentaram progressivamente. }\end{array}$ & $\begin{array}{l}\text { Aumento de volume } \\
\text { dos linfonodos me- } \\
\text { sentéricos. }\end{array}$ & $\begin{array}{l}\text { Distensão e vacuolização citoplasmática nas } \\
\text { células de Purkinje do cerebelo, nos neurô- } \\
\text { nios do córtex cerebral, do mesencéfalo e } \\
\text { do corno ventral da medula espinhal. }\end{array}$ & NA \\
\hline 5 & 75 & 25 & $\begin{array}{l}\text { No HR Test sinais clínicos neurológicos } \\
\text { com hiperestesia, tremor, quedas cons- } \\
\text { tantes e olhar atônito. Postura de cavale- } \\
\text { te e tremor intencional. }\end{array}$ & $\begin{array}{l}\text { Aumento de volume } \\
\text { dos linfonodos me- } \\
\text { sentéricos e emaciação. }\end{array}$ & $\begin{array}{l}\text { Distensão e vacuolização citoplasmática nas } \\
\text { células de Purkinje do cerebelo, nos } \\
\text { neurônios do córtex cerebral, do tálamo, } \\
\text { do mesencéfalo e do corno ventral da } \\
\text { medula espinhal. }\end{array}$ & NA \\
\hline 6 & 80 & 24 & $\begin{array}{l}\text { Fezes pastosas, tremor intencional e } \\
\text { hiperestesia, olhar atônito, acentuação da } \\
\text { resposta ao HR Test, quedas constantes, } \\
\text { dificuldade de apreender os alimentos, } \\
\text { emaciação e apatia. A partir do décimo- } \\
\text { primeiro dia sem consumir a planta, os } \\
\text { sinais clínicos diminuíram gradativamente } \\
\text { em intensidade. }\end{array}$ & $\begin{array}{l}\text { Aumento de volume } \\
\text { dos linfonodos me- } \\
\text { sentéricos e emaciação. }\end{array}$ & $\begin{array}{l}\text { O cerebelo apresentou discreta vacuolização } \\
\text { no citoplasma das células de Purkinje e } \\
\text { esferóides axonais na camada granular. }\end{array}$ & $\begin{array}{l}\text { Dilatação do retí- } \\
\text { culo endoplasmá- } \\
\text { tico rugoso das cé- } \\
\text { lulas de Purkinje } \\
\text { do cerebelo. }\end{array}$ \\
\hline 7 & 100 & 43 & $\begin{array}{l}\text { Fezes pastosas, apatia, inapetência, difi- } \\
\text { culdade para se levantar e ficar em esta- } \\
\text { ção, tremor intencional, dificuldade para } \\
\text { apreender e mastigar os alimentos, posi- } \\
\text { ção de cavalete e resposta acentuada HR } \\
\text { Test. }\end{array}$ & $\begin{array}{l}\text { Emaciação, escara de } \\
\text { decúbito e aumento } \\
\text { de volume dos linfo- } \\
\text { nodos mesentéricos. }\end{array}$ & $\begin{array}{l}\text { Distensão e vacuolização citoplasmática nas } \\
\text { células de Purkinje do cerebelo, nos } \\
\text { neurônios do córtex cerebral, do tálamo, } \\
\text { do mesencéfalo e do corno ventral da } \\
\text { medula espinhal. }\end{array}$ & $\begin{array}{l}\text { Vacuolizações ci- } \\
\text { toplasmáticas, al- } \\
\text { gumas envoltas } \\
\text { por membranas em } \\
\text { neurônios de Pur- } \\
\text { kinje do cerebelo e } \\
\text { nas células foli- } \\
\text { culares da tireóide. }\end{array}$ \\
\hline
\end{tabular}

a Início dos sinais clínicos, ${ }^{\text {b }}$ Sem alterações, ${ }^{c}$ Não analisado.-

coletados para microscopia eletrônica. Esses tecidos foram fixados em solução de glutaraldeído a $2 \%$ tamponado em cacodilato de sódio, refixados em tetróxido de ósmio a $1 \% \mathrm{e}$ desidratados em soluções crescentes de etanol e incluídos em Epon. Os cortes semifinos foram corados pelo azul de metileno e os ultrafinos foram contrastados com acetato de uranila e citrato de chumbo e examinados em microscópio eletrônico de transmissão.

\section{RESULTADOS}

\section{Sinais clínicos}

Detalhes dos achados clínicos e patológicos estão relacionados no Quadro 2. Os principais sinais clínicos nos ovinos afetados eram relacionados com o sistema nervoso central e consistiram de ataxia com dismetria, tremores de cabeça e pescoço, quedas freqüientes e posturas atípicas escorando-se em objetos, às vezes com membros cruzados. Notou-se também lentidão de movimentos, perda progressiva de peso e dificuldades para apreender, mastigar e deglutir alimentos.
O Ovino 1 não apresentou sinais clínicos e foi encontrado morto no $18^{\circ}$ dia de experimento.

Tremores, quedas, decúbito lateral, movimentos de pedalagem e dificuldade para ficar em estação no HR Test, foram notados nos Ovinos 2, 5, 6 e 7, em média, a partir do $20^{\circ}$ dia do início do experimento. Tremor intencional foi observado a partir do 25을 dia do início do experimento nos Ovinos 2, 3, 4, 5 e 6. Esta alteração consistia em discreto e freqüente tremor da cabeça, que era regular durante o repouso e se tornava mais intenso durante a alimentação ou manejo. Os Ovinos 5, 6 e 7 apresentaram dificuldade de ficar em estação em torno do $45^{\circ}$ dia, e ficavam em posição de cavalete (Fig. 1).

O Ovino 6 consumiu Sida carpinifolia por um período de 80 dias, suspendendo-se o consumo por 70 dias. Quando a planta foi suprimida da dieta, os sinais clínicos diminuíram gradativamente em intensidade e não foram mais notados a partir do $11^{\circ}$ dia sem consumir a planta.

O Ovino 7, comeu S. carpinifolia, por 100 dias, apresentou os primeiros sinais clínicos após o $43^{\circ}$ dia de consumo notan- 

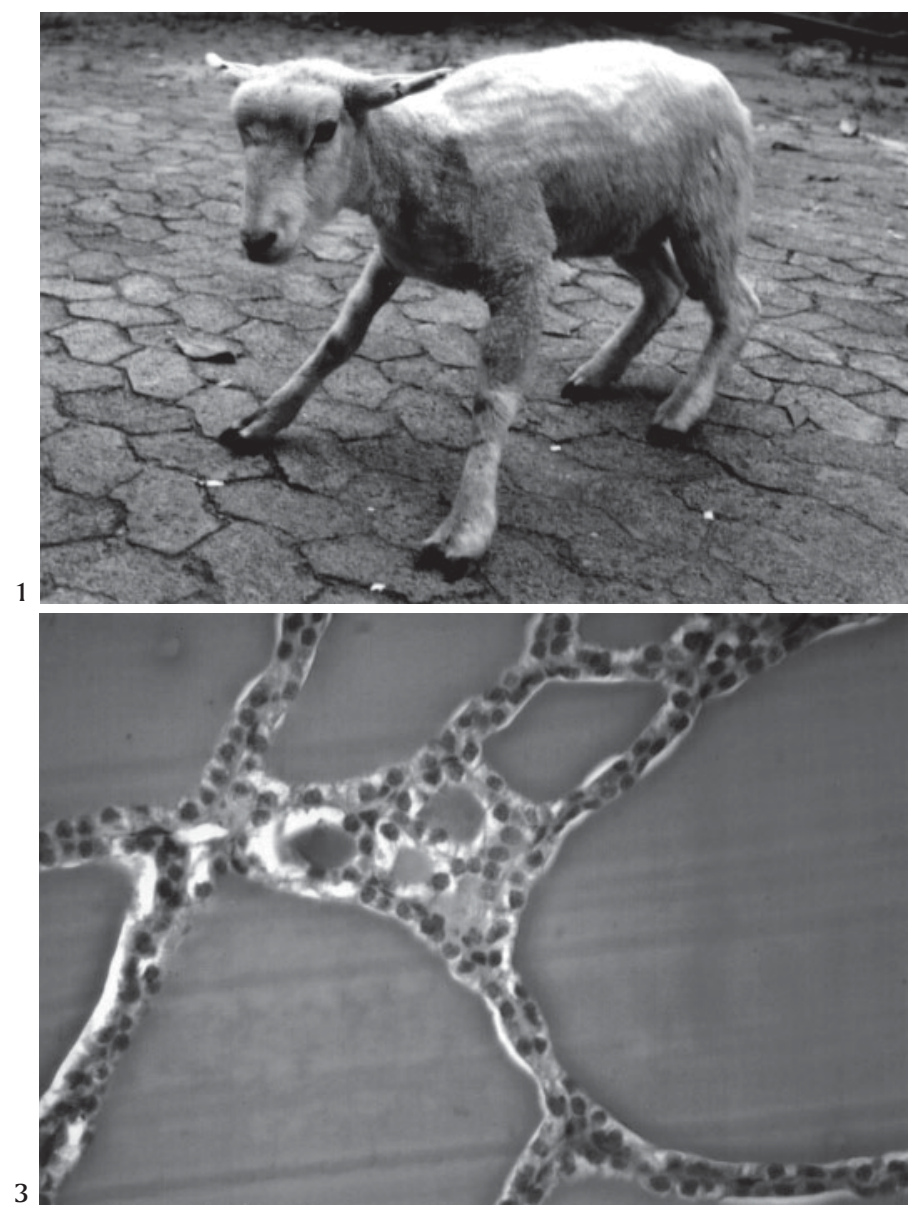

Fig.1. Animal com dificuldade de permanecer em estação, posição de cavalete, na intoxicação experimental por Sida carpinifolia (Ovino 6).

Fig.3. Vacuolização citoplasmática nas células foliculares da tireóide, colóide com aspecto normal, na intoxicação experimental por Sida carpinifolia (Ovino 5). HE, obj. 40.

do-se apatia, inapetência, dificuldade para se levantar e ficar em estação. Seis dias depois apresentou tremor intencional, dificuldade para apreender e mastigar os alimentos. Os sinais clínicos neurológicos se mostraram progressivamente mais intensos. Quando abaixava a cabeça para se alimentar, pressionava a cabeça no fundo do cocho. Ao beber água, as narinas freqüentemente eram submersas no bebedouro, e o animal rapidamente levantava a cabeça e espirrava. A partir do $80^{\circ}$ dia, o animal ficava a maior parte do tempo deitado, em decúbito esternal, desenvolvendo escara de decúbito na região do esterno.

Nos Ovinos 2, 4, 5, 6 e 7 as fezes apresentaram-se pastosas a levemente diarréicas durante 2 dias, ao redor do $20^{\circ}$ dia, e voltavam a consistência normal.

\section{Achados de necropsia e histopatológicos}

A única alteração observada na necropsia foi aumento de volume de linfonodos, principalmente dos mesentéricos. Nos demais órgãos, não foram notadas alterações significativas.
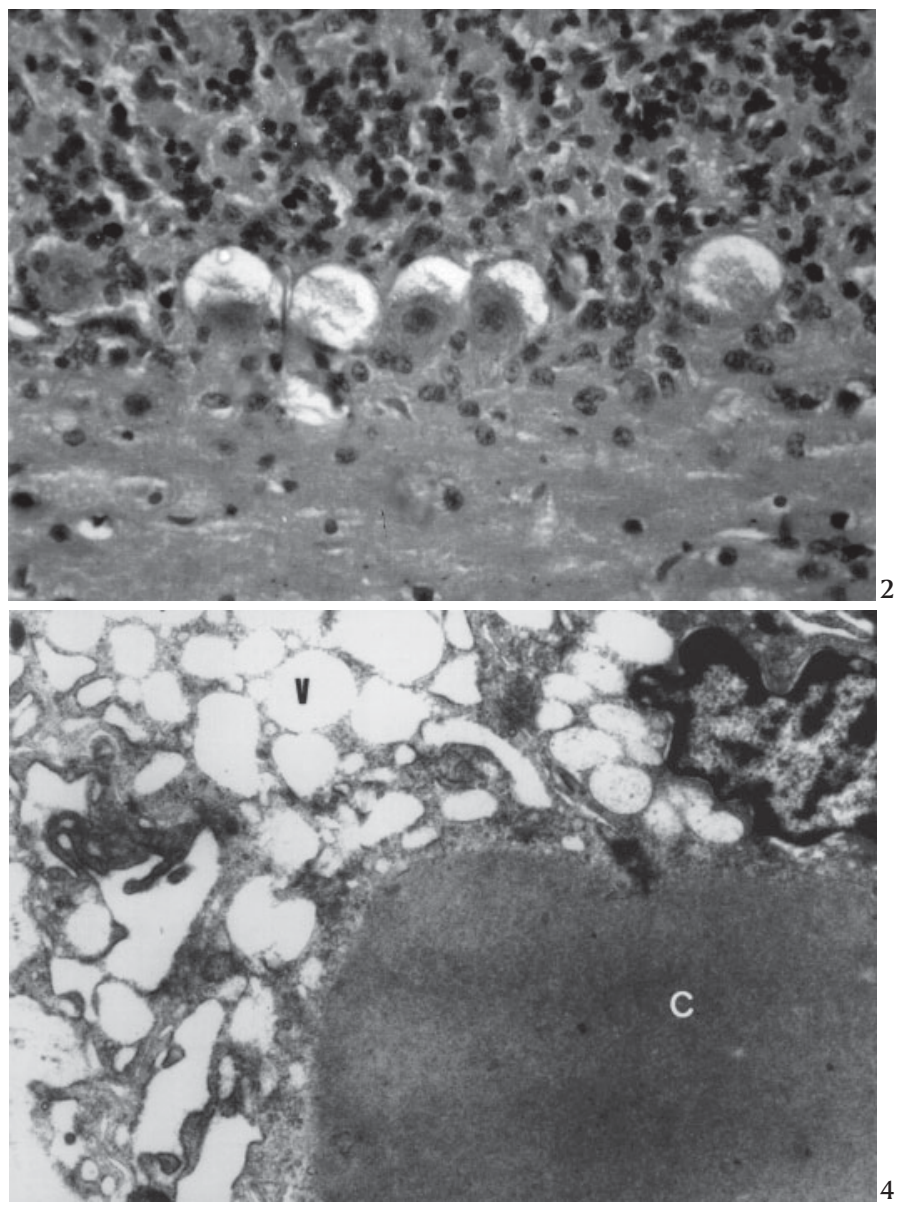

Fig. 2. Distensão e vacuolização citoplasmática múltipla e acentuada nas células de Purkinje do cerebelo, pela intoxicação experimental por Sida carpinifolia (Ovino 4). HE, obj. 25.

Fig. 4. Tireóide com vacuolização das células foliculares (V), apresentando colóide de aspecto normal (C), na intoxicação experimental por Sida carpinifolia (Ovino 7). ME, $10.500 \mathrm{x}$.

Microscopicamente, o Ovino 1 apresentou apenas vacuolização nos neurônios do corno ventral da medula espinhal, na região cervical. Nos Ovinos 2, 3, 4 e 5, os achados mais significativos foram observados no sistema nervoso central e caracterizaram-se por distensão e vacuolização citoplasmática múltipla e acentuada, mais evidentes nas células de Purkinje do_cerebelo (Fig. 2), nos neurônios do córtex cerebral, do tálamo, do mesencéfalo e do corno ventral da medula espinhal, em algumas destas células, praticamente todo citoplasma era vacuolizado permanecendo apenas pequenas áreas de citoplasma eosinofilico que ocupava a periferia da célula. Esferóides axonais foram freqüientemente encontrados na camada granular do cerebelo e, com menor intensidade, em outras áreas do encéfalo e medula espinhal. O cerebelo do Ovino 6 apresentou discreta vacuolização no citoplasma das células de Purkinje e esferóides axonais na camada granular. Vacuolização citoplasmática no epitélio dos ácinos pancreáticos, dos túbulos renais, nas células foliculares da tireóide (Fig. 3), nos hepatócitos e macrófagos de órgãos linfóides foi observado nos Ovinos 3, 4, 5 e 7. Os cére- 
bros dos ovinos controles não apresentaram nenhuma das alterações histológicas observadas nos animais experimentais.

\section{Achados ultra-estruturais}

As lesões ultra-estruturais observadas foram vacuolizações citoplasmáticas, algumas envoltas por membranas em neurônios de Purkinje do cerebelo e nas células foliculares da tireóide do Ovino 7 (Fig. 4). O Ovino 6, que permaneceu 70 dias sem consumir S. carpinifolia, possuía apenas dilatação do retículo endoplasmático rugoso das células de Purkinje do cerebelo.

\section{DISCUSSÃO}

Este trabalho comprovou que o consumo experimental de Sida carpinifolia por ovinos causa doença de armazenamento lisossomal. O quadro clínico e patológico é similar ao descrito na intoxicação natural por S. carpinifolia em ovinos (Seitz et al. 2002) e caprinos (Driemeier et al. 2000, Colodel 2002a). Alterações clínicas e patológicas similares, em ovinos, foram descritas em casos de consumo espontâneo de plantas dos gêneros Swainsona sp (Laws \& Anson 1968, Dorling et al. 1980), Oxytropis sp (Stegelmeier et al. 1995, Stegelmeier et al. 1999), Astragalus sp (James et al. 1981, Harris et al. 1988) e Ipomoea sp (Balogh et al. 1999, Tokarnia et al. 2000). Este estudo evidencia que $S$. carpinifolia não perde sua toxicidade quando é secada à sombra e que nestas condições, é tóxica para ovinos na quantidade mínima de $14 \mathrm{~g} / \mathrm{kg}$ ao dia, quando consumida durante 18 dias.

Os sinais clínicos observados nos ovinos experimentais e também em casos espontâneos (Seitz et al. 2002), foram menos evidentes quando comparados aos caprinos (Colodel et al. 2002a). Sinais clínicos pouco definidos em ovinos foram também observados na intoxicação experimental por Ipomoea fistulosa (Tokarnia et al. 2000).

O consumo médio diário da $S$. carpinifolia secada à sombra, capaz de causar sinais clínicos e lesões neurológicas foi de $20 \mathrm{~g} /$ $\mathrm{kg}$, observado nos Ovinos 3, 4, 5 e 6 . 0 maior consumo médio diário da planta foi de $30 \mathrm{~g} / \mathrm{kg}$ (Ovino 2) e o menor foi de $11 \mathrm{~g} / \mathrm{kg}$ (Ovino 7). Alterações clínicas neurológicas são as principais manifestações de ovinos intoxicados por S. carpinifolia. Foi observado que o consumo médio diário de $30 \mathrm{~g} / \mathrm{kg}$ de S. carpinifolia secada à sombra é capaz de induzir os sinais clínicos de lesões neurológicas, se consumida no período mínimo de 30 dias seguidos. Períodos maiores de consumo da planta, mesmo em quantidades menores, podem causar lesões e sinais clínicos mais intensos, conforme observado no Ovino 7. As alterações de equilíbrio, associadas com ataxia e dismetria, são características de lesões cerebelares e puderam ser comprovadas também HR Test. Essas lesões consistiram histologicamente de vacuolização das células de Purkinje e esferóides axonais na camada granular do cerebelo e são comuns em $\alpha$-manosidoses induzidas (Dorling et al. 1980).

A swainsonina inibe a atividade da $\alpha$-manosidase de forma mais intensa, quando consumida de maneira contínua e prolongada (Balogh et al. 1999). A ingestão de plantas com o alcalóide swainsonina, quando constituir ao redor de $50 \%$ da dieta diária durante 6 a 8 semanas, induz a doença clínica neurológica em ovinos, bovinos e eqüinos (Huxtable \& Dorling 1982).

Resultados observados neste experimento, com regressão de sinais clínicos 11 dias após um período de consumo de 80 dias de S. carpinifolia e ausência de alterações patológicas (Ovino 6), sugere que animais naturalmente afetados pelo consumo da planta podem se recuperar quando retirados de áreas invadidas pela planta. A dilatação do retículo endoplasmático, verificada ultraestruturalmente neste animal, foi considerado um achado inespecífico.

Foi observada grande variação individual dos animais em relação ao consumo de S. carpinifolia. Os Ovinos 6 e 7, durante a fase inicial do experimento, consumiram a planta com voracidade enquanto que os demais demoraram a se adaptar à nova dieta, buscando selecionar apenas feno de alfafa e ração comercial. Esse fato foi também observado em surtos naturais de caprinos onde alguns animais buscavam pastorear S. carpinifolia, mesmo com outros alimentos à disposição (Colodel et al. 2002a).

Foram observadas lesões histológicas no Ovino 1, que consumiu S. carpinifolia durante 18 dias, mesmo sem o animal apresentar sinais clínicos. A presença das alterações histológicas sem sinais clínicos também foi verificada em caprinos (Driemeier et al. 2000).

Agradecimentos.- Agradecemos à Dra. Olinda Leites Bueno, da Fundação Zoobotânica do Rio Grande do Sul, pela identificação da planta.

\section{REFERÊNCIAS}

Agamanolis D.P. 1995. The pathology of lysosomal storage diseases. Pathol. Annu. 30:247-285.

Armién A.G. 2000. Vergleichende klinische und morphologische Untersuchungen zur spontanen und experimentellen Vergiftung durch Ipomoea fistulosa (Convolvulaceae) bei Ziegen. Tese de doutorado, JustusLiebig-Universität Giessen, Alemanha. 212p.

Bacchi O., Leitão Filho H.F. \& Aranha C. 1982. Plantas invasoras de culturas. Vol.1. Círculo do Livro, Campinas, SP. 291p.

Balogh K.K.I.M., Dimande A.P., Lugt J.J., Molyneux R.J., Naudé T.W. \& Welman W.G. 1999. A lisosomal storage disease induced by Ipomoea carnea in goats in Mozambique. J. Vet. Diagn. Invest. 11:266-273.

Booth N.H. \& McDonald L.E. 1992. Farmacologia e Terapêutica em Veterinária. 6 $6^{\underline{a}}$ ed. Guanabara Koogan, Rio de Janeiro, p.928-932.

Colodel E.M., Driemeier D., Loretti A.P., Gimeno E.J., Traverso S.D., Seitz A.L. \& Zlotowski P. 2002a. Aspectos clínicos e patológicos da intoxicação por Sida carpinifolia (Malvaceae) em caprinos no Rio Grande do Sul. Pesq. Vet. Bras. 22(2):51-57.

Colodel E.M., Gardner D.R., Zlotowski P. \& Driemeier D. 2002b. Identification of swainsonina as a glycose inibidor responsible for Sida carpinifolia poisoning. Vet. Hum. Toxicol. 44(3):177-178.

Conselho Federal de Medicina Veterinária do Brasil 2002. Resolução CFMV $\mathrm{n}^{\mathrm{o}} \mathbf{7 1 4}$, de 20 de junho de 2002.

Dorling P.R, Huxtable C.R. \& Colegate S.M. 1980. Inhibition of lysosomal alpha-mannosidase by swainsonine, an indolizidine alkaloid isolated from Swainsona canescens. Biochem. J. 191(2):649-651.

Driemeier D., Colodel E.M., Gimeno E.J. \& Barros S.S. 2000. Lysosomal storage disease caused by Sida carpinifolia poisoning in goats. Vet. Pathol. 37(2):153-159.

Harris C.M., Campbell B.C., Molyneux R.J. \& Harris T.M. 1988. Biosynthesis of swainsonine in the diablo locoweed (Astragalus oxyphysus). Tetrahedrom Let. 29(38):4815-4818.

Henriques A.T., Siqueira N., Schapoval E.E.S., Guterres S. \& Dalla Costa T.C.T. 1989. Análise farmacognóstica preliminar e atividade antiinflamatória das folhas de Sida carpinifolia (L.f.) K.Schum., Malvaceae (Parte I). Ver. Bras. Farm., São Paulo, 70(3):55-58. 
Huxtable C.R. \& Dorling P.R. 1982. Animal model of human disease. Mannosidosis. Swainsonine-induced mannosidosis. Am. J. Pathol. 107(1):124-126.

James L.F., Hartley W.J. \& Van-Kampen K.R. 1981. Syndromes of Astragalus poisoning in livestock. J. Am. Vet. Med. Assoc. 178(2):146-150.

King N.W. \& Alroy J. 2000. Deposições intracelulares e extracelulares; degenerações, p.27-59. In: Jones T.C., Hunt R.D. \& King N.W. (ed.) Patologia Veterinária. 6 $6^{\underline{a}}$ ed. Manole, São Paulo.

Laws L. \& Anson R.B. 1968. Neuronopathy in sheep fed Swainsona luteola and S. galegifolia. Aust. Vet. J. 44:447-452.

Lorenzi H. 2000a. Manual de Identificação e de Controle de Plantas Daninhas: Plantio Direto e Convencional. $5^{\underline{a}}$ ed. Plantarum Ltda, Nova Odessa, SP. 339p.

Lorenzi H. 2000b. Plantas Daninhas do Brasil: Terrestres, Aquáticas, Parasitas, Tóxicas e Medicinais. $5^{\underline{a}}$ ed. Plantarum Ltda, Nova Odessa, SP, p.471-478.

Loretti A.P., Colodel E.M., Gimeno E.J. \& Driemeier D. 2003. Lysosomal storage disease in Sida carpinifolia toxicosis: an induced mannosidosis in horses. Eq. Vet. J. 35(5):434-438.

Massone F. 1999. Anestesiologia Veterinária: Farmacologia e Técnicas. $3^{\underline{a}}$ ed. Guanabara Koogan, Rio de Janeiro. 225p.
Moremen K.W. 2002. Golgi alpha-mannosidase II deficiency in vertebrate systems: implications for asparagines-linked oligosaccharide processing in mammals. Bioch. Bioph. Acta 1573:225-235.

Pienaar J.G., Kellerman T.S., Basson P.A., Jenkins W.L. \& Vahrmejer J. 1976. Maldronksiekte in cattle: a neuronopathy caused by Solanum kwebense N.E. Br. Onderstepoort J. Vet. Res. 43(2):67-74.

Prophet E.B., Mills B., Arrington J.B. \& Sobin L.H. 1992. Laboratory Methods in Histotechnology. Armed Forces Institute of Pathology, Washington, DC. $279 \mathrm{p}$.

Seitz A.L., Gimeno E.J., Traverso S.D., Schmitz M., Zlotowski P., Colodel E.M. \& Driemeier D. 2002. Intoxicação espontânea por Sida carpinifolia (Malvaceae) em ovinos. XXIX Congr. Bras. Med. Vet., 10-14 out., Gramado, RS. (Resumo CCP 702)

Stegelmeier B.L., James L.F., Panter K.E. \& Molyneux R.J. 1995. Tissue and serum swainsonine concentrations in sheep ingesting Astragalus lentiginosus (locoweed). Vet. Hum. Toxicol. 37(4):336-339.

Stegelmeier B.L., James L.F., Panter K.E., Gardner D.R., Pfister J.A., Ralphs M.H. \& Molyneux R.J. 1999. Dose response of sheep poisoned with locoweed (Oxytropis sericea). J. Vet. Diag. Invest. 11:448-456.

Tokarnia C.H., Döbereiner J. \& Peixoto P.V. 2000. Plantas Tóxicas do Brasil. Editora Helianthus, Rio de Janeiro. 310p. 